\title{
Accounting for underlying complexities identifies simple hierarchy of trait-environment relationships in Wisconsin forest understory communities
}

\author{
Andres Rolhauser ${ }^{1}$, Don Waller ${ }^{2}$, and Caroline Tucker ${ }^{3}$ \\ ${ }^{1}$ CONICET \\ ${ }^{2}$ Univ. of Wisconsin - Madison \\ ${ }^{3}$ University of North Carolina-Chapel Hill
}

November 23, 2020

\begin{abstract}
Adaptive relationships between traits and the environment are often inferred from observational data by regressing communityweighted mean (CWM) traits on environmental gradients. However, trait-environment relationships are better understood as the outcome of trait-abundance and environment-abundance relationships, and the interaction between traits and the environment. Accounting for this functional structure and for interrelationships among traits should improve our ability to accurately describe general trait-environment relationships. Using forest understory communities in Wisconsin, we applied a generalized mixed model (GLMM) incorporating this structure. We identified a simple hierarchy of trait-environment relationships dominated by a strong positive effect of mean temperature on plant height. Compared to the traditional CWM approach, the GLMM was more conservative in identifying significant trait-environment relationships, and also detected important relationships that CWM regressions overlooked. This work highlights the need to consider the complexity underlying trait-environment relationships in future analyses
\end{abstract}

\section{Hosted file}

Rolhauser, Waller \& Tucker Ecol Let.pdf available at https://authorea.com/users/378102/ articles/494671-accounting-for-underlying-complexities-identifies-simple-hierarchy-oftrait-environment-relationships-in-wisconsin-forest-understory-communities 